\title{
CARACTERIZACIÓN DE AISLAMIENTOS DE Colletotrichum lindemuthianum DE ECUADOR Y GUATEMALA PARA IDENTIFICAR GENES DE RESISTENCIA ${ }^{1}$
}

\author{
Halima Awale ${ }^{2}$,Esteban Falconí-Castillo ${ }^{3}$, Julio Cesar Villatoro-Mérida ${ }^{4}$, James Kelly ${ }^{2}$
}

\begin{abstract}
RESUMEN
Caracterización de aislamientos de Colletotrichum lindemuthianum de Ecuador y Guatemala para identificar genes de resistencia. El objetivo de esta investigación fue determinar la variabilidad patogénica de $C$. lindemuthianum en zonas productoras de frijol común en Ecuador y Guatemala para identificar las combinaciones de genes de resistencia más efectivas para las condiciones locales. Aislamientos de antracnosis recolectados fueron caracterizados para la identificación de las razas presentes en estos países empleando el juego estándar de 12 cultivares diferenciales. De acuerdo a la evaluación, solamente dos razas $(5,9)$ mostraron estar presentes en los dos países. En Guatemala se registró una mayor diversidad patogénica (mayor número de razas) que en Ecuador. Basados en esta información y en otros datos de estudios realizados anteriormente, sugerimos como la combinación genética más efectiva la piramidación de los genes $\mathrm{Co}-\mathrm{I}^{2}$ y $\mathrm{Co}-4^{2}$. Esta combinación conferiría resistencia completa a casi todas las razas de $C$. lindemuthianum identificadas hasta el momento en los dos países.
\end{abstract}

Palabras clave: Acervo genético, antracnosis, cultivares diferenciales, razas, piramidación de genes.

\begin{abstract}
Characterization of isolates of Colletotrichum lindemuthianum from Ecuador and Guatemala to identify resistance genes. The objective of this study was to determine the pathogenic variability of $C$. lindemuthianum in the bean production zones of Ecuador and Guatemala in order to identify the most effective combination of resistance genes for local conditions. Isolates of anthracnose were characterized for race structure based on 12 differential cultivars. Only two races $(5,9)$ were common between countries and greater pathogenic variability (larger number of races) was observed in Guatemala than in Ecuador. Based on this information and data from previous collection studies, we suggest that pyramiding the $\mathrm{Co}^{-1} \mathrm{I}^{2}$ and $\mathrm{Co}-4^{2}$ genes from different gene pools is the most effective gene combination. This combination would provide complete resistance to all currently known races of anthracnose present in both countries.
\end{abstract}

Key words: Gene pool, anthracnose, differential cultivars, races, gene pyramiding.

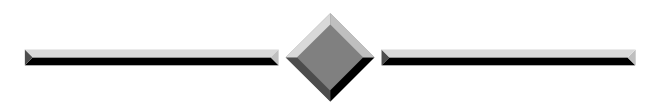

\section{INTRODUCCIÓN}

La antracnosis ocasionada por Colletotrichum lindemuthianum es una de las enfermedades de frijol común más importantes a nivel mundial. Las pérdidas en rendimiento pueden alcanzar hasta un $90 \%$ cuando variedades susceptibles de frijol son cultivadas en presencia del patógeno, bajo condiciones ambientales favorables para el desarrollo del mismo (Pastor-Corrales et al. 1994). La diseminación del patógeno entre las

Recibido: 2 de mayo, 2007. Aceptado: 18 de enero, 2008.

2 Crop and Soil Sciences, Michigan State University, East Lansing MI 48824, USA, Tel: (517)-355-0271, Correo electrónico: kellyj@msu.edu

3 Instituto Nacional de Investigaciones Agropecuarias INIAP, Estación Experimental Santa Catalina. Panamericana Sur Km 14, Quito, Ecuador. Tel: (593)-2-2693360, Correo electrónico: legumin@pi.pro.ec

4 Instituto de Ciencia y Tecnología Agrícola ICTA, Chimaltenango, Guatemala. Tel: (502)-6630-5705, Correo electrónico: juliocevillatoro@ hotmail.com 
zonas de producción es causada principalmente por la siembra y trasiego de semillas infectadas (PastorCorrales et al. 1995). La resistencia genética de la mayoría de cultivares comerciales ha sido ineficiente y poco durable debido al gran número de razas existentes y a las que continuamente se desarrollan dentro de la especie del patógeno (Balardin et al. 1997, Kelly et al. 1994, Kelly y Vallejo 2004). Una estrategia para incrementar la durabilidad y eficiencia de la resistencia a $C$. lindemuthianum es la piramidación de varios $\mathrm{Co}^{-}$ genes en los cultivares de frijol, una vez que, el espectro de virulencia de las distintas razas del hongo en la región sea conocido, para así recomendar la combinación de genes de resistencia más adecuada (Young et al. 1998). El objetivo de esta investigación fue determinar la variabilidad presente en el patógeno $C$. lindemuthianum en zonas productoras frijoleras de Ecuador y Guatemala para definir las combinaciones de genes de resistencia más efectivas para las condiciones locales.

\section{MATERIALES Y MÉTODOS}

Diecinueve aislamientos de $C$. lindemuthianum fueron caracterizados empleando el sistema binario estandarizado basado en la reacción del grupo de 12 cultivares diferenciales (Pastor-Corrales 1991; Cuadro 1). Siete de estos aislamientos provinieron de Ecuador y doce de Guatemala (Cuadro 2). Las muestras de tejido infectado correspondieron a tallos o vainas que mostraron síntomas de antracnosis. Cada muestra fue cortada en trozos pequeños, cuyas superficies fueron esterilizadas (Cloro $1 \%$, Etanol $70 \%$ en agua destilada). Los trozos de tejido fueron secados y colocados en platos Petri conteniendo medio de cultivo Mathur o Papa-Dextrosa-Agar (Balardin et al. 1997).

Los aislamientos fueron incubados a $22{ }^{\circ} \mathrm{C}$ hasta que presentaron esporulación. Posteriormente fueron replicados en varios Petri conteniendo medio de Mathur para su eventual almacenamiento y uso en el futuro. El inóculo fue preparado mediante la adición de agua destilada a cada plato Petri, seguido por el raspado mediante una varilla de metal. La suspensión de esporas fue filtrada empleando gasa quirúrgica y cuantificada en un hemocitómetro. La concentración final fue ajustada a $1,2 \times 10^{6}$ esporas $/ \mathrm{ml}$. Seis semillas de cada cultivar diferencial fueron sembradas en bandejas y, aproximadamente diez días después de la siembra, las plántulas fueron inoculadas. Los aislamientos fueron inoculados individualmente e, inmediatamente después, las plántulas fueron ubicadas en una cámara húmeda durante 48 horas. Las plántulas fueron evaluadas diez días después de la inoculación utilizando una

Cuadro 1. Código binario, genes de resistencia y acervo genético de origen de los cultivares diferenciales empleados en la caracterización de razas de Colletotrichum lindemuthianum. Ecuador y Guatemala. 2005.

\begin{tabular}{|c|c|c|c|c|}
\hline Cultivares diferenciales & Letra código & Valor binario & Gen de resistencia & Acervo genético $^{\mathrm{a}}$ \\
\hline Michelite & A & 1 & Co-11 & MA \\
\hline Michigan Dark Red Kidney & B & 2 & Co-1 & A \\
\hline Perry Marrow & $\mathrm{C}$ & 4 & $\mathrm{Co}-1^{3}$ & A \\
\hline Cornell 49-242 & $\mathrm{D}$ & 8 & Co-2 & MA \\
\hline Widusa & $\mathrm{E}$ & 16 & $\mathrm{Co}-1^{5}$ & A \\
\hline Kaboon & $\mathrm{F}$ & 32 & $\mathrm{Co}-1^{2}$ & A \\
\hline Mexico 222 & G & 64 & Co-3 & MA \\
\hline PI 207262 & $\mathrm{H}$ & 128 & $\mathrm{Co}-4^{3} \mathrm{Co}-9$ & MA \\
\hline TO & I & 256 & Co-4 & MA \\
\hline $\mathrm{TU}$ & $\mathrm{J}$ & 512 & Co-5 & MA \\
\hline AB 136 & K & 1024 & Co-6 & MA \\
\hline G2333 & $\mathrm{L}$ & 2048 & $\mathrm{Co}-4^{2} \mathrm{Co}_{-} 5^{2} \mathrm{Co}-7$ & MA \\
\hline
\end{tabular}

${ }^{\mathrm{a}} \mathrm{MA}=$ Mesoamericano; $\mathrm{A}=$ Andino 
Cuadro 2. Aislamientos, razas, origen y cultivar hospedero de Colletotrichum lindemuthianum de Ecuador y Guatemala. 2005.

\begin{tabular}{|c|c|c|c|c|}
\hline $\begin{array}{l}\text { Aisla- } \\
\text { miento }\end{array}$ & Raza & Origen & $\begin{array}{c}\text { Cultivar } \\
\text { hospedero }\end{array}$ & $\begin{array}{c}\text { Acervo } \\
\text { genético }^{\text {a }}\end{array}$ \\
\hline EC 1 & 1031 & $\begin{array}{c}\text { Tumbaco, } \\
\text { Ecuador } \\
\text { Poblado entre }\end{array}$ & CAP-9 & MA \\
\hline EC 2 & 4 & Ibarra y San & Paragachi & A \\
\hline EC 3 & 4 & $\begin{array}{c}\text { Gabriel, Ecuador } \\
\text { Cráter Pululahua, } \\
\text { Ecuador }\end{array}$ & $\begin{array}{c}\text { Voluble } \\
\text { local }\end{array}$ & A \\
\hline EC 4 & 13 & $\begin{array}{l}\text { San Miguel de } \\
\text { Pisquer, Ecuador }\end{array}$ & $\begin{array}{c}\text { Canario } \\
\text { Local }\end{array}$ & A \\
\hline EC 5 & 7 & Tambo, Ecuador & ACE-1 & A \\
\hline EC 6 & 5 & $\begin{array}{l}\text { Mira Ángel, } \\
\text { Ecuador }\end{array}$ & $\begin{array}{l}\text { Descono- } \\
\text { cido }\end{array}$ & A \\
\hline EC 7 & 12 & Asquér, Ecuador & $\begin{array}{c}\text { Descono- } \\
\text { cido }\end{array}$ & A \\
\hline GU 1 & 520 & $\begin{array}{c}\text { Patzicia, } \\
\text { Guatemala }\end{array}$ & $\begin{array}{c}\text { ICTA Al- } \\
\text { tense }\end{array}$ & MA \\
\hline GU 2 & 1024 & $\begin{array}{l}\text { Chimaltenango, } \\
\text { Guatemala }\end{array}$ & $\begin{array}{l}\text { Descono- } \\
\text { cido }\end{array}$ & MA \\
\hline GU 3 & 1024 & $\begin{array}{l}\text { Chimaltenango, } \\
\text { Guatemala }\end{array}$ & $\begin{array}{l}\text { Descono- } \\
\text { cido }\end{array}$ & MA \\
\hline GU 4 & 1097 & $\begin{array}{l}\text { Chimaltenango, } \\
\text { Guatemala }\end{array}$ & $\begin{array}{l}\text { Descono- } \\
\text { cido }\end{array}$ & MA \\
\hline GU 5 & 9 & $\begin{array}{c}\text { Chimaltenango, } \\
\text { Guatemala }\end{array}$ & $\begin{array}{l}\text { Descono- } \\
\text { cido }\end{array}$ & MA \\
\hline GU 6 & 1024 & $\begin{array}{l}\text { Chimaltenango, } \\
\text { Guatemala }\end{array}$ & $\begin{array}{l}\text { Descono- } \\
\text { cido }\end{array}$ & MA \\
\hline GU 7 & 1024 & $\begin{array}{l}\text { Chimaltenango, } \\
\text { Guatemala }\end{array}$ & $\begin{array}{l}\text { Descono- } \\
\text { cido }\end{array}$ & MA \\
\hline GU 8 & 1545 & $\begin{array}{l}\text { Patzicia, } \\
\text { Guatemala }\end{array}$ & $\begin{array}{l}\text { ICTA Al- } \\
\text { tense }\end{array}$ & MA \\
\hline GU 9 & 521 & $\begin{array}{l}\text { Patzicia, } \\
\text { Guatemala }\end{array}$ & $\begin{array}{l}\text { Descono- } \\
\text { cido }\end{array}$ & MA \\
\hline GU 10 & 520 & $\begin{array}{l}\text { Chimaltenango, } \\
\text { Guatemala }\end{array}$ & Arbustivo & MA \\
\hline GU 11 & 1544 & $\begin{array}{l}\text { Parramos, } \\
\text { Guatemala }\end{array}$ & $\begin{array}{l}\text { Voluble } \\
\text { (agricultor) }\end{array}$ & MA \\
\hline GU 12 & 648 & $\begin{array}{c}\text { Chimaltenango, } \\
\text { Guatemala }\end{array}$ & $\begin{array}{c}\text { Voluble } \\
\text { (agricultor) }\end{array}$ & MA \\
\hline
\end{tabular}

a Acervo genético del hospedero: MA= Mesoamericano; $\mathrm{A}=$ Andino

escala de 1-9, en la cual 1-3= resistente /incompatible y 4-9= susceptible/compatible (Balardin et al. 1997).

\section{RESULTADOS Y DISCUSIÓN}

Con base en la reacción de los 12 cultivares diferenciales, se identificaron las siguientes razas: 4,5 , 7, 12, 13, 1031, 9, 520, 521, 648, 1024, 1097, 1544 y 1545 (Cuadro 3). Dentro de estas catorce razas, seis corresponden a aislamientos provenientes de Ecuador y ocho de Guatemala, siendo las razas 5 y 9 las únicas razas en común entre los dos países. La raza 5 vence la resistencia de los genes $\mathrm{Co}-1^{3}$ y $\mathrm{Co}-11$, mientras que la raza 9 infecta a los genotipos de frijol que poseen los genes $\mathrm{Co}$-2 y $\mathrm{Co}$-11. Las razas mencionadas son genéticamente diferentes, pero tienen un gen de virulencia en común (Avr-Co-11). El alelo $C o-1^{3}$ es reconocido como el alelo de resistencia más débil de los alelos que se encuentran en el locus andino Co-1, mientras que el gen $\mathrm{Co}$-2 se encuentra entre los más ampliamente empleados de los genes $\mathrm{Co}$ - para el mejoramiento de la resistencia a antracnosis (Kelly y Vallejo 2004). Todos los aislamientos ecuatorianos evaluados fueron virulentos para el cultivar Perry Marrow y la raza 4 fue la más frecuente en este grupo de aislamientos. Las razas ecuatorianas también fueron virulentas sobre los cultivares diferenciales Michigan Dark Red Kidney (Co1), Cornell 49242 (Co-2) y AB136 (Co-6). Las razas más frecuentes, entre los aislamientos de Guatemala, fueron las razas 520, 1024 y 1544. Las razas de Guatemala mostraron que poseen más genes de virulencia que las razas andinas y presentaron compatibilidad con los genes mesoamericanos $\mathrm{Co}-2, \mathrm{Co}-3, \mathrm{Co}-4, \mathrm{Co}-$ 5 y Co-6. Ninguna de las razas guatemaltecas mostró compatibilidad con el acervo genético Andino, ubicados en el locus $\mathrm{Co}-1$.

Estos resultados sugieren que existió una relación entre el origen geográfico y la variabilidad patogénica de las razas de antracnosis. De los diecinueve aislamientos evaluados, ninguno fue virulento sobre los cultivares Widusa, Kaboon, TO o G2333. Por otro lado, Cornell 49242 fue susceptible a diez razas, seguido por AB 136 y Michelite, los cuales fueron susceptibles a ocho razas. Michigan Dark Red Kidney fue susceptible a dos razas de Ecuador, pero ninguna de las razas de Guatemala logró infectarlo. Mexico 222 y PI 207262 fueron susceptibles a tan sólo una raza, mientras el diferencial TU, el cual posee el gen Co-5, fue susceptible a seis razas de Guatemala. En Ecuador, estudios previos han identificado a las razas 3, 4, 256, $260 \mathrm{y}$ 1346 (Falconí et al. 2003) y razas 0, 1, 4, 5, 6, 9, 15, 
Cuadro 3. Reacción de los cultivares diferenciales de frijol (A-L) a 19 aislamientos de Colletotrichum lindemuthianum de Ecuador y Guatemala. 2005.

\begin{tabular}{|c|c|c|c|c|c|c|c|c|c|c|c|c|c|}
\hline $\begin{array}{l}\text { Aislamiento } \\
\text { de Ecuador }\end{array}$ & Raza $^{a}$ & $\begin{array}{l}A^{b} \\
(1)\end{array}$ & $\begin{array}{l}\text { B } \\
(2)\end{array}$ & $\begin{array}{l}C \\
(4)\end{array}$ & $\begin{array}{l}\text { D } \\
(8)\end{array}$ & $\begin{array}{c}E \\
(16) \\
\end{array}$ & $\begin{array}{c}F \\
(32)\end{array}$ & $\begin{array}{l}G \\
(64)\end{array}$ & $\begin{array}{c}\mathbf{H} \\
(\mathbf{1 2 8}) \\
\end{array}$ & $\begin{array}{c}I \\
(256)\end{array}$ & $\begin{array}{c}\mathbf{J} \\
(\mathbf{5 2 1}) \\
\end{array}$ & $\begin{array}{c}\mathrm{K} \\
(\mathbf{1 0 2 4})\end{array}$ & $\begin{array}{c}\mathrm{L} \\
(2048)\end{array}$ \\
\hline EC 1 & 1.031 & + & + & + & - & - & - & - & - & - & - & + & - \\
\hline EC 2 & $4^{\mathrm{cd}}$ & - & - & + & - & - & - & - & - & - & - & - & - \\
\hline EC 3 & $4^{\mathrm{cd}}$ & - & - & + & - & - & - & - & - & - & - & - & - \\
\hline EC 4 & 13 & + & - & + & + & - & - & - & - & - & - & - & - \\
\hline EC 5 & 7 & + & + & + & - & - & - & - & - & - & - & - & - \\
\hline EC 6 & $5^{d}$ & + & - & + & - & - & - & - & - & - & - & - & - \\
\hline EC 7 & 12 & - & - & + & + & - & - & - & - & - & - & - & - \\
\hline $\begin{array}{l}\text { Aislamiento de } \\
\text { Guatemala }\end{array}$ & $\mathbf{R a z a}^{\mathrm{a}}$ & $\begin{array}{l}A^{b} \\
(1)\end{array}$ & $\begin{array}{l}\text { B } \\
(2)\end{array}$ & $\begin{array}{l}\text { C } \\
(4)\end{array}$ & $\begin{array}{l}\mathrm{D} \\
(\mathbf{8})\end{array}$ & $\begin{array}{c}E \\
(16) \\
\end{array}$ & $\begin{array}{c}F \\
(32) \\
\end{array}$ & $\begin{array}{c}G \\
(64)\end{array}$ & $\begin{array}{c}\mathrm{H} \\
(\mathbf{1 2 8}) \\
\end{array}$ & $\begin{array}{c}I \\
(256) \\
\end{array}$ & $\begin{array}{c}\mathbf{J} \\
(\mathbf{5 2 1}) \\
\end{array}$ & $\begin{array}{c}\mathrm{K} \\
(\mathbf{1 0 2 4}) \\
\end{array}$ & $\begin{array}{c}\mathrm{L} \\
(\mathbf{2 0 4 8}) \\
\end{array}$ \\
\hline GU 1 & 520 & - & - & - & + & - & - & - & - & - & + & - & - \\
\hline GU 2 & 1024 & - & - & - & - & - & - & - & - & - & - & + & - \\
\hline GU 3 & 1024 & - & - & - & - & - & - & - & - & - & - & + & - \\
\hline GU 4 & 1097 & + & - & - & + & - & - & + & - & - & - & + & - \\
\hline GU 5 & $9^{d}$ & + & - & - & + & - & - & - & - & - & - & - & - \\
\hline GU 6 & 1024 & - & - & - & - & - & - & - & - & - & - & + & - \\
\hline GU 7 & 1024 & - & - & - & - & - & - & - & - & - & - & + & - \\
\hline GU 8 & $1545^{\mathrm{d}}$ & + & - & - & + & - & - & - & - & - & + & + & - \\
\hline GU 9 & 521 & + & - & - & + & - & - & - & - & - & + & - & - \\
\hline GU 10 & 520 & - & - & - & + & - & - & - & - & - & + & - & - \\
\hline GU 11 & 1544 & - & - & - & + & - & - & - & - & - & + & + & - \\
\hline GU 12 & 648 & - & - & - & + & - & - & - & + & - & + & - & - \\
\hline
\end{tabular}

a Designación de razas basada en el sistema de nomenclatura binaria. Sumatoria de números binarios “+” = Número de raza.

${ }^{\mathrm{b}}$ Diferenciales de frijol común empleados para la identificación de razas de $C$. lindemuthianum seguidos por la letra y el valor binario ( ) mostrado en el Cuadro 1.

c Previamente reportado por Falconi et al. (2003).

d Previamente reportado por Muhuku et al. (2004).

e Previamente reportado por Muhuku mediante comunicación personal (CIAT).

$65,128,129,133,256,261$ y 1153 (Mahuku y Riascos 2004). En el presente estudio, solamente la raza 4 fue identificada nuevamente. En Guatemala, estudios similares identificaron a las razas 9, 73, 1025, 1545, 1549, 1645 (Mahuku y Riascos 2004) en adición a las razas 5, 585, 641, 1032, 1088, 1572, 1609, 1929 (Mahuku, comunicación personal) [Las razas en negrilla fueron detectadas en el presente estudio, Cuadro 3].

\section{Estrategias de mejoramiento para Ecuador y Gua- temala}

Muchas veces, el elevado número de razas de antracnosis causa confusión a los mejoradores para la selección de las mejores fuentes de resistencia, y comúnmente consideran que genes individuales de resistencia son necesarios para controlar razas individuales. Sin embargo, la estrategia más efectiva es seleccionar aquellos genes y/o alelos con el más amplio rango de resistencia. Cuando se estudia la variabilidad genética de $C$. lindemuthianum, ilustrada por diferentes razas del patógeno, es importante agrupar las razas por los genes de virulencia similares/diferentes que ellas poseen. Por ejemplo, las razas 521 y 1.545 parecen muy distintas al basarse en su código binario, ya que el gene de virulencia, Avr-Co-6 vence la resistencia del gene Co-6 en el diferencial AB-136 (1024). En este sentido, tan solo un gen puede proveer resistencia a las dos razas en mención. En contraste, las razas 2047 y 2048 parecen cercanas, pero difieren en trece genes de virulencia Avr-Co-1, $1^{2,3,4,5}, 2,3,4,4^{3}, 5,6,9,11$ presentes en la raza 2047 y tres genes de virulencia AvrCo- $4^{2}, \mathrm{Co}-5^{2}, \mathrm{Co}-7$ presentes en la raza 2048. 
Es importante hacer esta distinción para seleccionar la mejor combinación de genes de resistencia. De acuerdo a este ejemplo, una combinación de genes diferentes sería requerida para proveer resistencia a cada raza.

Para facilitar la selección de la combinación más efectiva en mejoramiento para la resistencia, hemos agrupado las razas de acuerdo con la mayor presencia de genes de virulencia ( $A v r_{-}$) que poseen para simplificar la elección de los mejores genes de resistencia (Cuadro 4). Debido a que varios alelos existen en los loci $\mathrm{Co}-1$, Co-3, Co-4 y Co-5, los mejoradores necesitan escoger los alelos más efectivos de cada locus. En muchos casos la elección es fácil; así por ejemplo, la selección de los alelos $\mathrm{Co}-\mathrm{I}^{2}$ y $\mathrm{Co}-4^{2}$ para conferir resistencia amplia a razas presentes en los dos acervos genéticos de frijol (Balardin et al. 1997, Young et al. 1998). Los alelos en los loci Co-3/Co-9 y Co-5 son menos claros y por ello la elección necesita ser específica a las razas presentes en la región (Kelly y Vallejo 2004, Mahuku y Riascos 2004, Rodríguez-Suárez et al. 2007). Adicionalmente, los mejoradores necesitan considerar todos los estudios pasados y presentes acerca de la variabilidad patogénica en sus regiones de producción. Como está ilustrado en el presente estudio, la ausencia de razas reportadas previamente puede ser debido a una limitación en el muestreo y no necesariamente la ausencia de la raza en el área de pro- ducción. La vigilancia continua es importante ya que la composición de razas puede cambiar de año a año.

\section{CONCLUSIONES}

Los resultados de este estudio muestran que Ecuador y Guatemala contrastan en términos de la variabilidad patogénica entre las razas detectadas. Las prácticas de mejoramiento dependerán de la disponibilidad de genes útiles de resistencia dentro del germoplasma local adaptado para cada país. Un énfasis del mejoramiento de frijol en Ecuador ha sido el expandir la variabilidad genética de las líneas andinas de semilla grande, las cuales poseen una estrecha base genética. En este sentido, una estrategia de mejoramiento para Ecuador debería incluir la incorporación de genes de resistencia mesoamericanos en cultivares locales élite. La mejor elección sería combinar el alelo Andino Co $-1^{2}$ con genes de resistencia del acervo genético mesoamericano, exceptuando los genes Co-2 y Co-6. A pesar de las diferencias en variabilidad patogénica entre países, las elecciones en el mejoramiento para la resistencia en Guatemala son similares a las recomendadas para Ecuador.

Todas las razas de Guatemala identificadas en este estudio fueron virulentas a diferenciales

Cuadro 4. Razas de Colletotrichum lindemuthianum agrupadas en base al mayor número de genes de virulencia (Avr) que poseen y la combinación de genes más efectiva para conferir resistencia. Ecuador y Guatemala. 2005.

\begin{tabular}{|c|c|c|c|}
\hline $\begin{array}{c}\text { Razas presentes en Ecuador } \mathbf{y} \\
\text { Guatemala }^{\mathrm{a}}\end{array}$ & $\begin{array}{c}\text { Combinación de genes } \\
\text { para resistencia }\end{array}$ & $\begin{array}{c}\text { Gen(es) opcionales de } \\
\text { resistencia }\end{array}$ & Genes Avr-mayores \\
\hline $1,3,4,5,6$ у 7 & $\mathrm{Co}-\mathrm{I}^{2}+\mathrm{Co}-4^{2}$ & Co-2, Co-3, Co-5, Co-6 у Co-9 & $\mathrm{Co}-1+\mathrm{Co}-1^{3}$ \\
\hline $9,12,13$ у 15 & $\mathrm{Co}-1^{2}+\mathrm{Co}-4^{2}$ & Co-3, Co-5, Co-6 у Co-9 & Co-2 \\
\hline 65 y 73 & $\mathrm{Co}-1^{2}+\mathrm{Co}-4^{2}$ & Co-5 у Co-6 & Co-3 \\
\hline $128,129,133,256,260$ у 261 & $\mathrm{Co}-1^{2}+\mathrm{Co}-4^{2}$ & Co-2, Co-3, Co-5 y Co-6 & Co-4 \\
\hline $520,521,585,641$ у 648 & $\mathrm{Co}-1^{2}+\mathrm{Co}-4^{2}$ & $\mathrm{Co}-1, \mathrm{Co}-4$ у $\mathrm{Co}-6$ & Co-5 \\
\hline $\begin{array}{l}1024,1025,1031,1032,1088 \\
1097,1153 \text { у } 1346\end{array}$ & $\mathrm{Co}-1^{2}+\mathrm{Co}-4^{2}$ & Co-5 & Co-6 \\
\hline $1544,1545,1549,1609$ у 1929 & $\mathrm{Co}-1^{2}+\mathrm{Co}-4^{2}$ & Co- 1, Co-3, Co-4 y Co-9 & $\mathrm{Co}-5+\mathrm{Co}-6$ \\
\hline 1572 y 1645 & $\mathrm{Co}-1+\mathrm{Co}-4^{2}$ & $\mathrm{Co}-1^{5}$ & $\mathrm{Co}-5+\mathrm{Co}-6+\mathrm{Co}-1^{2}$ \\
\hline
\end{tabular}

${ }^{a}$ Incluye razas previamente reportadas por Falconi et al. (2003) y Muhuku et al. (2004) y nuevas razas identificadas en el presente estudio. 
mesoamericanos que poseen los genes $\mathrm{Co}-2, \mathrm{Co}-5$ and Co-6. La incorporación de genes de resistencia andinos sería una estrategia útil para proveer de una resistencia efectiva a cultivares de Guatemala. La misma combinación de genes $\mathrm{Co}-\mathrm{I}^{2}$ y $\mathrm{Co}-4^{2}$ provee resistencia a la mayoría de razas de $C$. lindemuthianum presentes en Guatemala, con excepción de las razas 1572 y 1645. Si los mejoradores necesitan elegir entre los diferentes alelos presentes en el locus Co-1, la combinación de Co-1 y Co- $4^{2}$ provee resistencia a estas dos razas 1572 y 1645. Sin embargo, la combinación de los genes $C o$ $I^{2}$ y $C o-4^{2}$ ha sido identificada como la más efectiva y se encuentra disponible en líneas avanzadas de frijol negro del programa de mejoramiento de la Universidad Estatal de Michigan (MSU).

\section{LITERATURA CITADA}

Balardin, RS; Jarosz, AM; Kelly, JD. 1997. Virulence and molecular diversity in Colletotrichum lindemuthianum from South, Central and North America. Phytopathology: 87: 1184-1191.

Falconí, E; Ochoa, J; Peralta, E; Danial, D. 2003. Virulence patterns of Colletotrichum lindemuthianum in common bean in Ecuador. Annu. Rept. Bean Improv. Coop. 46:167-168.

Kelly, JD; Afanador, L; Cameron, LS. 1994. New races of Colletotrichum lindemuthianum in Michigan and implication in dry bean resistance breeding. Plant Dis. 78: 892-894.
Kelly, JD; Vallejo, VA. 2004. A comprehensive review of the major genes conditioning resistance to anthracnose in common bean. HortScience 39:1196-1207.

Mahuku, GS; Riascos, JJ. 2004. Virulence and molecular diversity within Colletotrichum lindemuthianum isolates from Andean and Mesoamerican bean varieties and regions. Eur. J. Plant Path. 110: 253-263.

Pastor-Corrales, MA. 1991. Estandarización de variedades diferenciales y de designación de razas de Colletotrichum lindemuthianum. Phytopathology 81:694 (Resumen).

Pastor-Corrales, MA; Erazo, O; Estrada, E; Singh, SP. 1994. Inheritance of anthracnose resistance in common bean accession G 2333. Plant Dis. 78:959-962.

Pastor-Corrales, MA; Otoya, MM; Molina, A; Singh, SP. 1995. Resistance to Colletotrichum lindemuthianum from Middle America and Andean South America in different common bean races. Plant Disease 79:63-67.

Rodríguez-Suárez C; Méndez-Vigo, B; Pañeda, A; Ferreira, JJ; Giraldez, R. 2007. A genetic linkage map of Phaseolus vulgaris L. and localization of genes for specific resistance to six races of anthracnose (Colletotrichum lindemuthianum). Theor. Appl. Genet. 114: $713-722$

Young, RA, Melotto, M; Nodari, RO; Kelly, JD. 1998. Marker assisted dissection of oligogenic anthracnose resistance in the common bean cultivar, G2333. Theor. Appl. Genet. 96:87-94. 